\title{
Significant Improvement in Quality of Life, Positive Effect on Sexuality, Lasting Reconstructive Result and Low Rate of Complications Following Cystocele Correction Using a Lightweight, Large-Pore, Titanised Polypropylene Mesh
}

Final Results of a National, Multicentre Observational Study

\section{Signifikante Verbesserung der Lebensqualität, positive Auswirkung auf die Sexualität, nachhaltiges rekonstruktives Ergebnis und geringe Komplikationsrate nach Zystozelenkorrektur mittels eines leichtgewichtigen, großporigen, titanisierten Polypropylennetzes}

Finale Ergebnisse einer nationalen, multizentrischen Beobachtungsstudie

\section{(ㄷ) (i) (오 $\ominus$}

\author{
Authors
}

Tina Cadenbach-Blome ${ }^{1}$, Markus Grebe ${ }^{2}$, Mathias Mengel $^{3}$, Friedrich Pauli ${ }^{4}$, Angelika Greser ${ }^{5}$, Christian Fünfgeld ${ }^{6}$

Deutsche Version unter:

https://doi.org/10.1055/a-0984-6614

\section{ABSTRACT}

Introduction Patients who suffer from pelvic organ prolapse can experience severe limitations in their quality of life. To improve the quality of life of women affected and achieve a stable reconstruction, surgical therapy is often indispensable. In conventional prolapse surgery, the rate of recurrence is high. For this reason, alloplastic mesh has been implanted increasingly in recent years to reconstruct the anatomy of the pelvic floor organs. Even if the anatomical result can be significantly improved as a result, the mesh-induced complications have been the subject of controversial discussion. In this national, multicentre study, the quality of life, anatomical result as well as the rate of complications following the implantation of an alloplastic mesh for the correction of a cystocele were investigated.

Method Fifty-four patients with symptomatic $\geq$ grade II were included in this prospective, national, multicentre study. The study participants were implanted with a titanised polypropylene mesh (TiLOOP ${ }^{\circledR}$ PRO A, pfm medical ag). The follow-up observation period was 12 months. Primary as well as repeat procedures were taken into account. The anatomic result of the pelvic floor reconstruction was quantified using the POP-Q system. Data on quality of life and sexuality were collected using validated questionnaires. All complications which occurred were documented and evaluated by an independent committee.

Results On average, the patients were in line with the census. An improvement in quality of life was able to be determined 
during the study in all domains investigated $(p<0.001$, Wilcoxon test). Minus incorrect entries and incorrect reports, a total of 19 reports of adverse events in 15 patients were evaluated by the end of the study. The rate of recurrence in the anterior compartment was $4.3 \%$.

Conclusion In the reconstruction of the anatomical position of the pelvic floor organs given the presence of a symptomatic cystocele, the implantation of a third-generation alloplastic mesh achieves very good results. Affected patients benefit from the anatomical stability as well as a significant improvement in quality of life, whereby the risks are justifiable.

\section{ZUSAMMENFASSUNG}

Einleitung Patientinnen, die unter einem Descensus genitalis leiden, können in ihrer Lebensqualität stark eingeschränkt sein. Um die Lebensqualität betroffener Frauen zu verbessern und eine stabile Rekonstruktion zu erreichen, ist häufig eine operative Therapie unumgänglich. Bei der konventionellen Deszensuschirurgie ist die Rezidivrate hoch. Daher wurden in den vergangenen Jahren zunehmend alloplastische Netze zur Rekonstruktion der Anatomie der Beckenbodenorgane implantiert. Auch wenn das anatomische Resultat dadurch deutlich verbessert werden konnte, führten die netzinduzierten Komplikationen zu einer kontroversen Diskussion. In dieser nationalen, multizentrischen Studie wurden die Lebensqualität, das anatomische Resultat sowie die Komplikationsrate nach Implantation eines alloplastischen Netzes zur Korrektur einer Zystozele untersucht.
Methode Vierundfünfzig Patientinnen mit symptomatischer Zystozele $\geq I^{\circ}$ wurden in diese prospektive, nationale, multizentrische Studie eingeschlossen. Den Studienteilnehmerinnen wurde ein titanisiertes Polypropylennetz (TiLOOP ${ }^{\circledR}$ PRO A, pfm medical ag) implantiert. Die Nachbeobachtungszeit betrug 12 Monate. Sowohl Primär- als auch Rezidiveingriffe wurden berücksichtigt. Das anatomische Ergebnis der Beckenbodenrekonstruktion wurde mittels POP-Q-System quantifiziert. Daten zur Lebensqualität und Sexualität wurden mittels validierten Fragebögen erfasst. Alle aufgetretenen Komplikationen wurden dokumentiert und von einem unabhängigen Komitee bewertet.

Ergebnisse Im Durchschnitt entsprachen die Patientinnen dem Zensus. Eine Verbesserung der Lebensqualität konnte während der Studie in allen untersuchten Domänen festgestellt werden ( $p<0,001$, Wilcoxon-Test). Abzüglich Fehleingaben und inkorrekter Berichte wurden bis zum Studienende insgesamt 19 Meldungen zu unerwünschten Ereignissen bei 15 Patientinnen bewertet. Die Rezidivrate im anterioren Kompartiment betrug 4,3\%.

Schlussfolgerung Bei der Rekonstruktion der anatomischen Lage der Beckenbodenorgane bei Vorhandensein einer symptomatischen Zystozele erzielt die Implantation eines alloplastischen Netzes der dritten Generation sehr gute Ergebnisse. Betroffene Patientinnen profitieren von der anatomischen Stabilität sowie einer signifikanten Verbesserung der Lebensqualität, wobei die Risiken vertretbar sind.

\section{Introduction}

Pelvic organ prolapse is one of the most common diseases in women. The risk of suffering prolapse increases with age, BMI, parity, physical stress over many years, and the stability of the connective tissue. In many age groups, nearly one out of four women is affected [1,2]. Not all women affected develop symptoms or perceive the symptoms to be detrimental. Others experience significant impairment of their quality of life due to a change in bladder and bowel function (symptoms of urgency, incontinence, voiding disorder), the feeling of a foreign body and/or dyspareunia, among others $[3,4]$. The lifetime risk for women to have to undergo surgical treatment due to pelvic organ prolapse is up to $20 \%$ [5]. Because of demographic changes in society, there will be an increase in the future in elderly women with symptomatic prolapse [6]. Therefore, for current and future patients, there should be a surgical therapy option with low rates of recurrence and complications, after conservative measures have been exhausted. The surgical reconstruction of the anterior compartment through tightening of autologous tissue, conventional anterior colporrhaphy, shows rates of recurrence of up to $50 \%[3,7,8]$. The implantation of alloplastic material significantly improves the anatomic result and significantly decreases the rate of recurrence [3, 9-11]. However, the mesh implantations were initially associated with a high rate of complications and adverse events, such as erosions, painful shrinkage of the implant, dyspareunia and also late infections $[3,9,12]$. Based on these experiences [12], the use of alloplastic implants in the treatment of prolapse has been the subject of controversial discussion. According to warnings [12] from the U.S. authority for food and drug safety (US Department of Health and Human Services, Food and Drug Administration [FDA]) in 2011, many manufacturers took their product off the market, in some cases only in the United States and in some cases worldwide. In the meantime, alloplastic implants have been prohibited by the FDA for the treatment of prolapse of the anterior compartment [13]. However, the numbers of mesh-aided surgeries have remained constant in Germany [14]. As a result of the further development of the implants (enlargement of the pores, reduction of the overall weight), increased experience on the part of the surgeons, and the improvement in the preparation and fixation techniques, it has been possible to reduce the number of complications $[3,15]$. Studies on these new implants have already shown a significantly reduced rate of complications and a significant improvement in quality of life, even beyond a postoperative period of up to 36 months for the newer implants $[11,16$, 17]. The primary endpoint of the study presented here was the change in quality of life 12 months postoperatively versus preoperatively in the case of symptomatic cystocele $\geq$ grade II following surgical correction by means of vaginal implantation of a titanised polypropylene mesh. The previous study with the titanised polypropylene mesh TiLOOP ${ }^{\circledR}$ Total 6 has already shown a significant improvement in quality of life following implantation of the 
mesh for the surgical correction of a cystocele $[11,17]$. The rates of recurrence and complications were low [11]. However, an erosion rate of $10.5 \%$ was seen [11]. The refined and optimised titanised polypropylene mesh TiLOOP ${ }^{\circledR}$ PRO A is to now be investigated within the scope of a multicentre observational study with regard to quality of life as well as the rate of complications and erosion. Due to the further improvement in material characteristics, it was assumed that the rate of complications, particularly with regard to the erosions which occur, would significantly decrease within 12 months postoperatively. The rate of complications was investigated as a secondary endpoint. The results of this investigation are presented below.

\section{Material and Methods}

\section{Study design and patients}

This national, prospective, multicentre observational study (national, multicentre post market surveillance study on anterior pelvic prolapse reconstruction with a titanium-coated polypropylene mesh [TiLOOP ${ }^{\circledR}$ PRO A]) was conducted at five German hospitals, sponsored by pfm medical ag. The inclusion criterion for study subjects was symptomatic pelvic organ prolapse in the anterior compartment, that is, a symptomatic cystocele $\geq$ grade II according to the classification of the International Continence Society (ICS) with the aid of the Pelvic Organ Prolapse Quantification (POP-Q-) system [18]. Patients could be included in a primary as well as in a recurrent situation. Exclusion criteria defined included family planning which had not yet been completed, a current oncological illness in the region of the pelvis/pelvic organs, current or previous radiation of the pelvis/pelvic organs, previously implanted mesh in the anterior compartment, and participation in another interventional study.

A total of 54 patients were included between February and August 2016. The study time period ended in August 2017 with the 12 -month follow-up of the last study subjects. All patients were cognitively able to understand the nature, issue, objective, benefits and risks of the study and study participation and independently fill out the necessary questionnaires. The study was explained to them in detail and in accordance with guidelines, and the patients were able to withdraw from participation in the study at any time. All data were collected in accordance with the federal data protection law. Prior to the start, the study was registered with the registry of the National Institutes of Health (NIH) (clinicaltrials.gov: NCT02690220) and reviewed and approved by the independent ethics committees in the respective federal states of the study centres. All complications (adverse events, AEs) were reviewed by an independent committee (clinical event committee, CEC). $100 \%$ monitoring of the study and supervision by the sponsor took place within the scope of an audit. The improvement in quality of life 12 months after the surgery, in comparison to before the surgery, was defined as the primary study objective. Secondary study objectives were the occurrence of serious and nonserious complications (serious adverse events [SAEs], non-serious $A E s)$, the feasibility of the surgery, and the quality of life 6 months after the implantation. The patients had clinical visits preoperatively and 6 and 12 months postoperatively. The prolapse and the postoperative anatomic result were documented in a standardised fashion using the POP-Q system $[18,19]$ and the quality of life, including changes in sexuality, were queried using the Prolapse Quality of Life (P-QoL) questionnaire validated in Germany $[20,21]$. In addition, the patients underwent clinical visits after 6 weeks.

\section{Implant and surgical technique}

Surgical treatment for the cystocele was performed via the vaginal implantation of a titanised polypropylene mesh (TiLOOP ${ }^{\circledR}$ PRO A, pfm medical ag). In comparison to the implant of the previous study (TiLOOP ${ }^{\circledR}$ Total 6), the pores of the TiLOOP ${ }^{\circledR}$ PRO-A implant used here were enlarged (from 1 to $3 \mathrm{~mm}$ ) and the weight was reduced (from 35 to $24 \mathrm{~g} / \mathrm{m}^{2}$ ). For the 6-point fixation, the introducer sheath was initially placed via transobturator and ischiorectal tunnelling following traditional preparation of the cystocele and then the arms of the mesh were threaded. The mesh was thus fixed distally in the obturator fascia, laterally on the arcus tendineus in the direct vicinity of the ischial spine and apically in the sacrospinal ligament in each case on the right as well as the left ( $\triangleright$ Fig. 1). All patients received perioperative antibiotic treatment; in addition, if necessary, the surgical treatment of the posterior compartment, hysterectomy and/or suburethral sling placement could be performed. Postoperatively, a local vaginal oestrogen treatment was prescribed.

\section{P-QoL questionnaire to determine quality of life, including sexuality}

In order to pre- and postoperatively assess the current symptoms of the prolapse, the severity of the impairment, the effects on the patients' quality of life and everyday life, the validated German P-QoL questionnaire was used [21,23]. In 40 questions, the current state of health, negative psychological and physical effects due to the prolapse, negative effects on role perception and the partner relationship as well as negative effects on sexuality, among others, are documented. The scale of results ranges from 0 (no impairment) to 100 (maximum impairment of quality of life). In order to more accurately record the changes in sexuality, some specifying questions on sexuality from the validated German pelvic floor questionnaire were supplemented [24], e.g. about dyspareunia or about the location of the pain during sexual intercourse. Patients were free to not answer individual or all questions about their quality of life. Sexually inactive patients answered the questions on sexuality with "no information possible".

\section{Anatomic assessment, clinical examination}

The preoperative stage of the prolapse and the postoperative result were documented according to the standardised, international prolapse classification of the ICS $[18,19]$. The POP-Q system defines 9 points in all 3 compartments, such as vaginal vault or cervix, which are measured in relation to the hymenal ring. In this way, defects can be assessed quantitatively and reproducibly according to site and degree of severity [20]. Prolapse in the anterior compartment $\geq$ grade II was defined as a recurrence. 


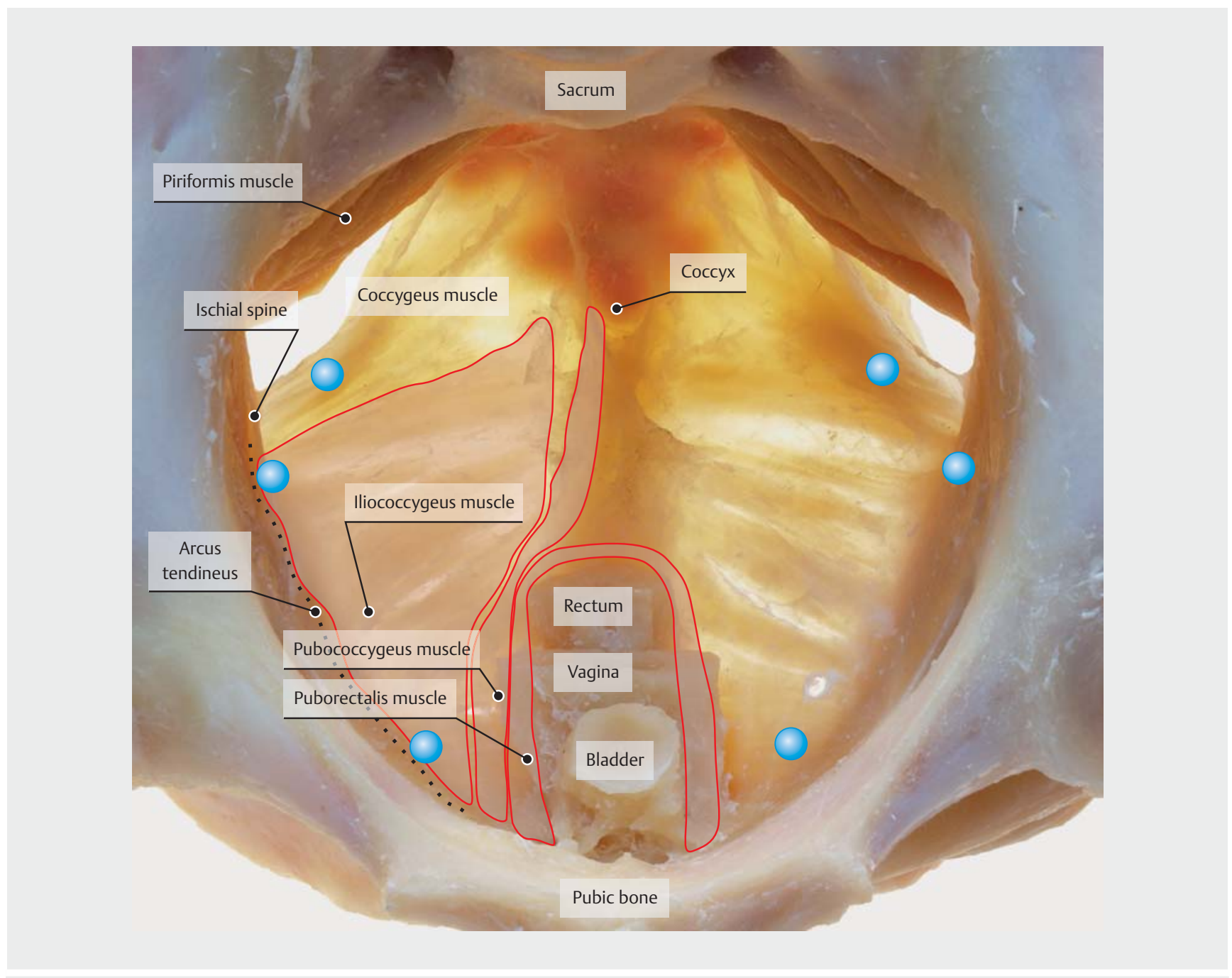

- Fig. 1 Fixation points of the mesh (blue markings). Figure from: Wedel T, Pauli F. Anatomische und chirurgische Grundlagen zur Netzrekonstruktion des Beckenbodens. Stuttgart: Thieme; 2010 [22], the blue marks of the fixation points were added.

\section{Clinical Event Committee}

The adverse events were assessed with the aid of the Common Terminology Criteria for Adverse Events (CTCAE, Version 0.4) [25] by an independent, external CEC. The participating experts had previously confirmed their independence through the disclosure of their (financial) interests and were selected based on their scientific and medical expertise.

\section{Statistics}

The statistical analysis was performed with IBM SPSS ${ }^{\circledR}$. The Wilcoxon test was used for the statistical analysis of the change in quality of life, including sexuality, between the pre- and postoperative time point. The comparison of two random samples was performed with the $x^{2}$ test and Fisher's exact test. The Wilcoxon test was used for the analysis of temporal progressions of dependent groups, for example, for the calculation of changes in the domains of the P-QoL questionnaire. The comparison of independent groups was calculated using the Kruskal-Wallis test, the paired comparison was calculated with the Mann-Whitney test.

\section{Results}

\section{Demographics}

The patients' demographic data were in line with the average from the census [26] and the data from German hospitals on diagnosis-related groups (DRG) provided by the Institute for the Hospital Remuneration System (InEK) [27]. On average, the patients were $67.5 \pm 8.3$ years old $(50-82)$, the BMI was $27.7 \pm 4.7 \mathrm{~kg} / \mathrm{m}^{2}$ (20.2-44.4). They had given birth to an average of 2.3 children $(0-4)$ and $90.4 \%(47 / 52)$ of the patients had had at least one vaginal delivery; only $1.9 \%(1 / 52)$ had a Caesarean section. One quarter of the patients had previously undergone pessary therapy (13/ $52,25.0 \%$ ) and/or pelvic floor training (14/52, 26.9\%). 30.8\% (16/ 52 ) of the patients had undergone hysterectomy and 13.5\% (7/ 52 ) had already had surgery due to prolapse. Of 54 patients included, 53 underwent surgery between February and August 2016. One patient had already withdrawn consent for study participation preoperatively. An alternative mesh implant was used 


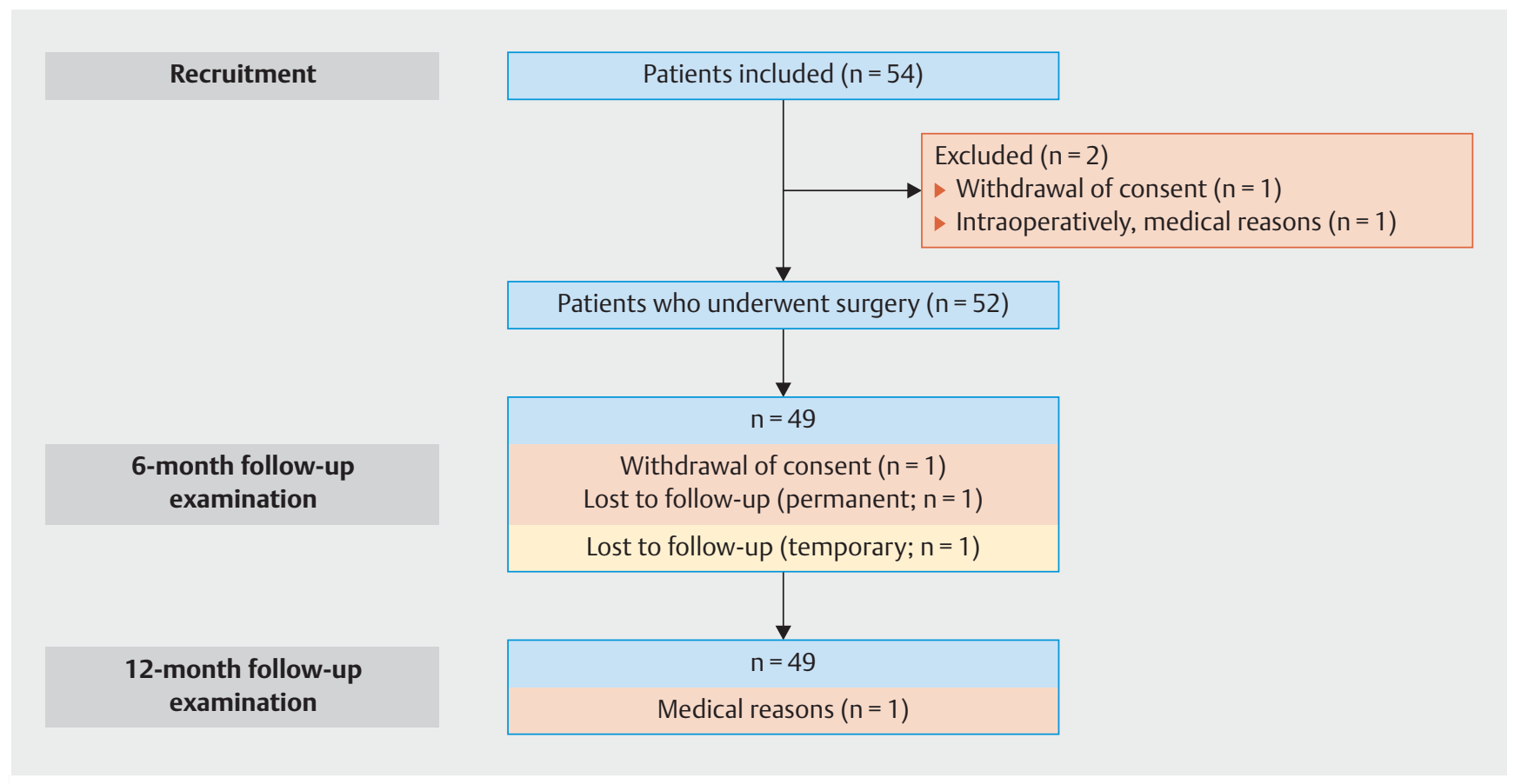

- Fig. 2 Diagram of study participants according to the CONSORT statement, 2010.

intraoperatively in one patient. Prior to the 6-month follow-up, one patient withdrew her consent for participation in the study due to (S)AEs. One patient had a stroke which led to the end of study participation. Thus 49 patients completed the 12-month follow-up, and of these patients, 46 completed the study as usual via a complete clinical visit and 3 via telephone interview. The patient cohort is explained in $\mathbf{F i g} \mathbf{2}$ in a diagram according to the CONSORT 2010 statement [28].

\section{Quality of life}

In the area of quality of life, the secondary endpoint of the previous study [11] could be confirmed here as the primary endpoint. A significant improvement in the quality of life was observed ( $p=0.001$, Wilcoxon test). Preoperatively, the negative impact on life due to the prolapse (83.3/100 points), the negative impact on roles and physical impairment (66.3 and 60.6/100 points) and the negative effects on the partner relationship (41.2/100 points) were the areas of patients' quality of life which were the most affected ( $\triangleright$ Fig. 3 ). At the 6-month follow-up, a significant improvement could already be determined in these 4 areas $(12.9,7.1$ and 9.5 [ $p<0.001$, Wilcoxon test] and 16.1 out of 100 points in each case $[p=0.009$, Wilcoxon test]). The 12-month follow-up demonstrated a further significant improvement as compared to the preoperative survey ( $\bullet$ Fig. $\mathbf{3}$ ). In the other areas investigated as well (general state of health, social limitation, mood, sleep and degree of symptoms) this significant improvement could be reproduced in both follow-ups (baseline vs. 12-month follow-up, out of 100 points in each case: 38.0 vs. $21.0 ; 25.2$ vs. $6.7 ; 34.7$ vs. $15.2 ; 38.3$ vs. $16.3 ; 50.8$ vs. 13.7$)$.

\section{Sexuality}

In addition to the 3 questions on the P-QoL on the topic of sexuality (negative effects on the partner relationship and/or sex life, vaginal bulging which hinders sexual intercourse), eight questions on sexuality from the validated German pelvic floor questionnaire were added to the sheet [24]. In addition to questions regarding vaginal dryness, intravaginal sensation, the sensation of vaginal width or narrowness, questions regarding pain during intercourse, location of pain and urine loss during intercourse were asked, among others. Preoperatively, 26.9\% (14/52) of the patients were sexually active. In the 12 -month follow-up, this figure was $44.9 \%$ (22/49). The assessment showed that no preoperatively active patients indicated sexual inactivity after 12 months. 71.2\% (37/52) of patients indicated being sexually inactive prior to the implantation, and of them, 15.4\% (8/52) indicated this was due to dyspareunia or problems during sexual intercourse. Other reasons for sexual inactivity included, among others, a lack of partnership, impotence on the part of the partner, and no interest. 50\% (25/ $50)$ of the patients indicated that the prolapse has a negative impact on sex life (10 mild, 7 moderate, 8 severe). In the 12-month follow-up, $51 \%$ (25/49) of the patients indicated being sexually inactive. Only one patient indicated dyspareunia as the reason for this. $16.7 \%(8 / 48)$ of the patients indicated that the prolapse has an influence on sex life (7 mild, 1 moderate), but only $8.7 \%(4 / 46)$ indicated that they perceived the prolapse as disruptive during intercourse. $>$ Fig. 4 shows the effects of the prolapse on sexual intercourse in the course of the study. 


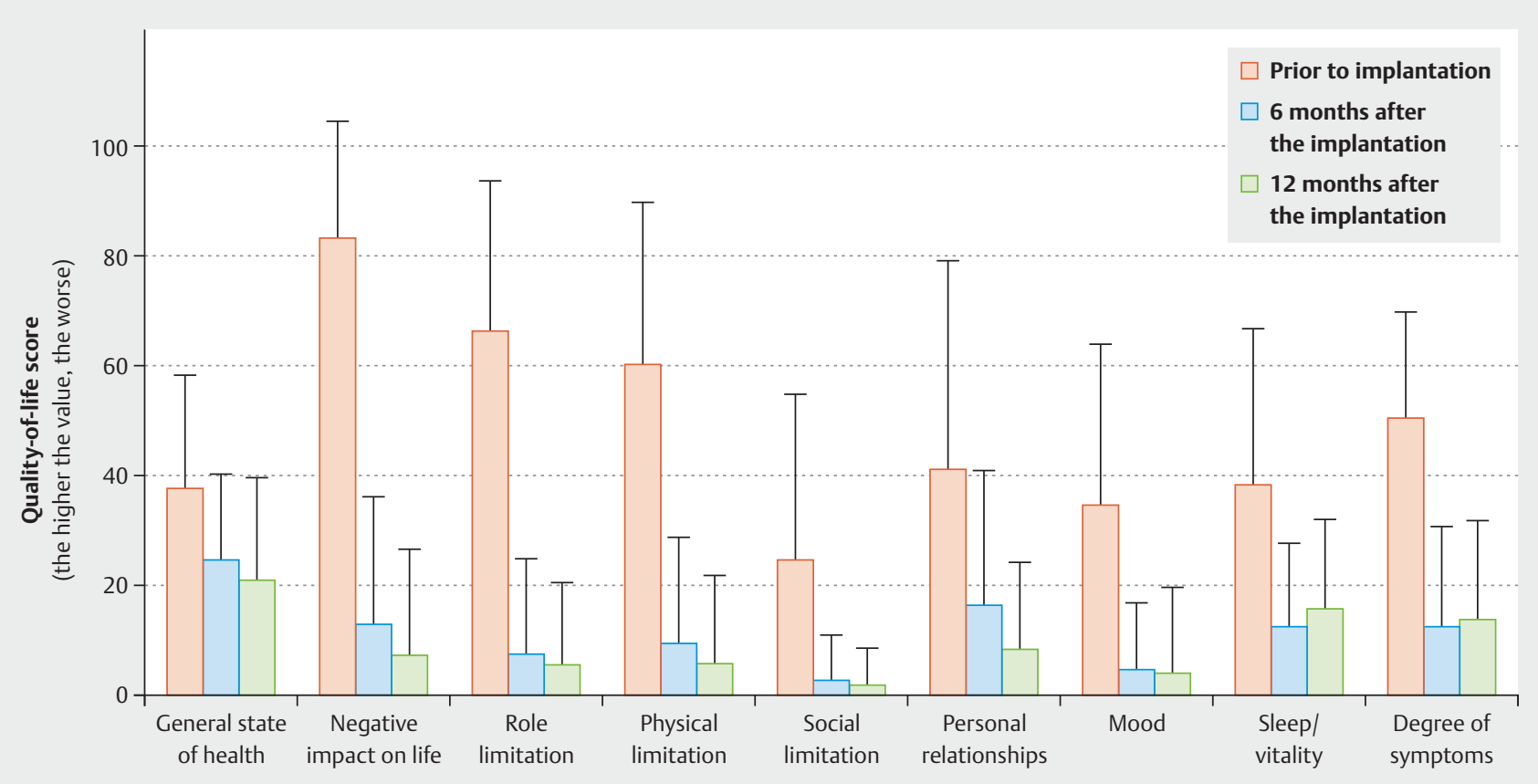

- Fig. 3 Quality of life before and after implantation of an alloplastic mesh. The value of the limitation in quality of life 6 and 12 months after the implantation in comparison to the limitation prior to the implantation is indicated, where 100 corresponds to the maximum limitation. The documentation of the quality of life is broken down into various areas.

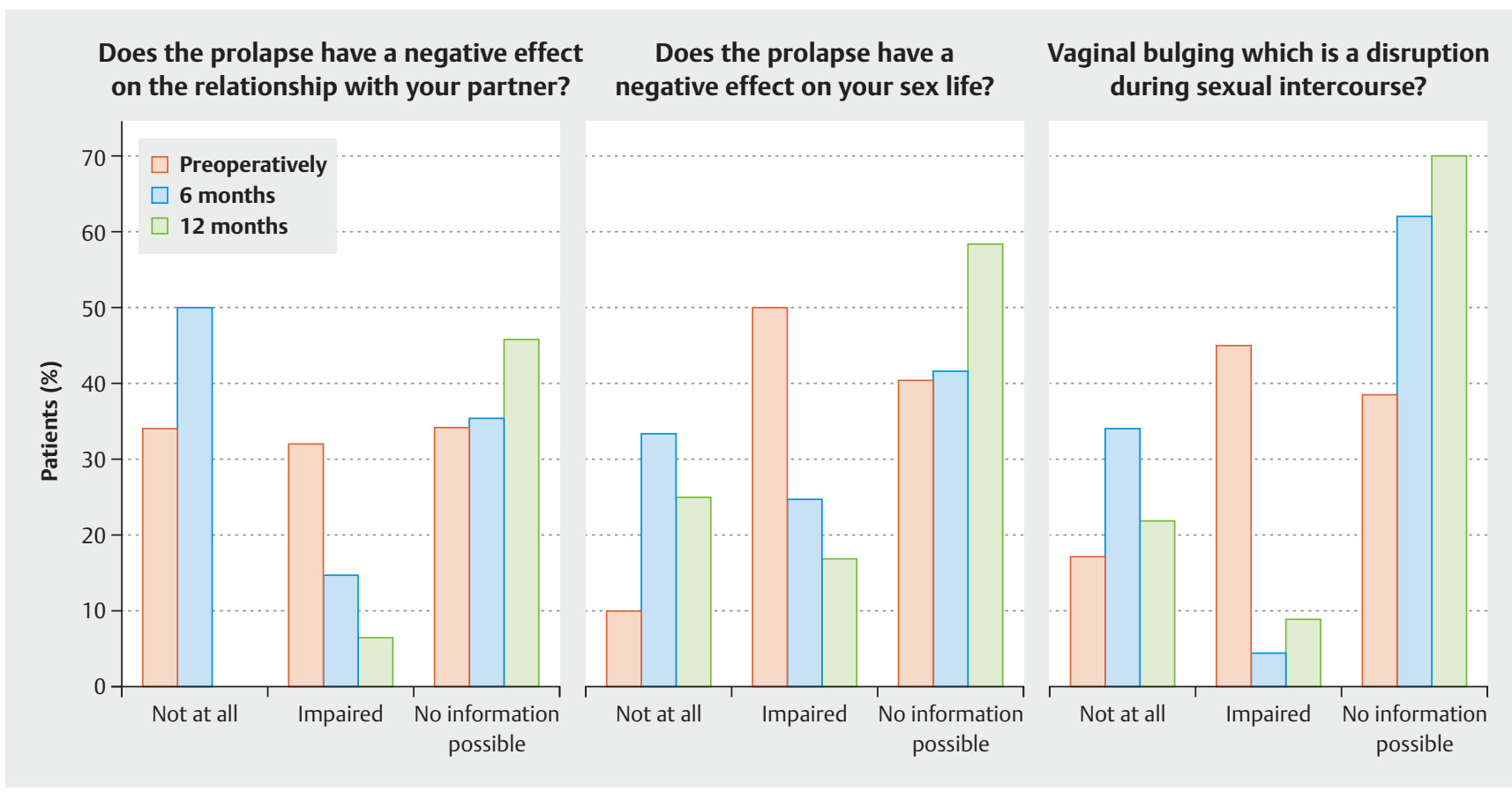

- Fig. 4 Improvement in sexual function after twelve months. Assessment of the questions on the negative effects in the relationship with the partner due to the prolapse, negative effects on sex life due to the prolapse, and whether the vaginal bulging is a disruption during sexual intercourse. Possible responses included: "Not at all", "Impaired" and "No information possible". The assessment was performed prior to the implantation as well as 6 and 12 months after the implantation. 


\section{Anatomic Result}

The degree of prolapse was classified according to the POP-Q system [19]. It significantly improved in all compartments and also with regard to overall status, after 6 as well as after 12 months. Preoperatively, $32.7 \%(17 / 52)$ of patients were diagnosed with a grade II cystocele and $67.3 \%$ (35/52) were diagnosed with a grade III cystocele. 86.5\% (45/52) of all patients demonstrated a prolapse of the apical compartment, uterus or vaginal stump (grade I-III). Prolapse of the posterior compartment (grade I-III) was diagnosed in $94.2 \%(49 / 52)$ of the patients. Only 5.8\% (3/52) had no prolapse of the posterior compartment. 3.8\% (2/52) of the patients suffered from grade IV prolapse. Simultaneous procedures to treat the prolapse in the posterior compartment were performed in $75.0 \%$ (39/52) of all surgeries; $57.7 \%$ (30/52) of them were a conventional posterior colporrhaphy, $17.3 \%(9 / 52)$ were a mesh-aided treatment (TiLOOP ${ }^{\circledR}$ PRO Plus P, pfm medical ag, Cologne). $13.5 \%$ (7/52) of all patients underwent a hysterectomy.

In the 6-month follow-up, 66.7\% (32/48) of the patients did not demonstrate any cystocele, $33.3 \%(16 / 48)$ had a grade I cystocele. Likewise, $66.7 \%(32 / 48)$ of the patients did not demonstrate any apical prolapse, while $29.2 \%(14 / 48)$ demonstrated grade I apical prolapse and $4.2 \%(2 / 48)$ had grade II prolapse. In the 12-month follow-up, $54.3 \%$ (25/46) of the patients did not demonstrate any cystocele, $41.3 \%$ (19/46) had a grade I cystocele ( $\triangleright$ Fig. 5). 69.6\% (32/46) of the patients did not demonstrate any apical prolapse, $26.1 \%$ (12/46) demonstrated grade I apical prolapse. At the 12-month follow-up, $4.3 \%$ (2/46) of the patients were diagnosed with a repeat grade II cystocele combined with an apical grade II prolapse and a prolapse in the posterior compartment. Preoperatively, both patients were status post hysterectomy and a posterior colporrhaphy was performed at the same time. At the 12-month follow-up, 37\% (17/46) of the patients did not demonstrate any prolapse in the posterior compartment; $43.5 \%$ (20/46) had grade I prolapse and 19.6\% (9/46) had grade II prolapse. Of the nine patients with posterior grade II prolapse at the 12-month follow-up, two already had prolapse of the posterior compartment preoperatively. Two patients did not have any concomitant procedures, 5 patients underwent posterior colporrhaphy, one patient underwent posterior colporrhaphy and a hysterectomy - this patient received a posterior mesh at a later point in time - and one patient underwent the concomitant implantation of a posterior mesh.

\section{Adverse Events}

An independent CEC evaluated each AE and allocated the corresponding organ class according to the CTCAE coding. AEs were documented at each point in time. By the end of the 12-month observation period, a total of 23 AEs were reported, of which 2 events were assessed by the CEC as incorrect entries and 2 as not being AEs. Ultimately, 19 AEs were documented in a total of 15 patients. Eleven events in 10 patients were defined as SAEs and 8 events in 6 patients were defined as non-serious AEs. None of the AEs was related to the product. Fourteen AEs were likely or definitively related to the procedure. All events were able to be allocated to a total of 8 different organ classes. Most patients were

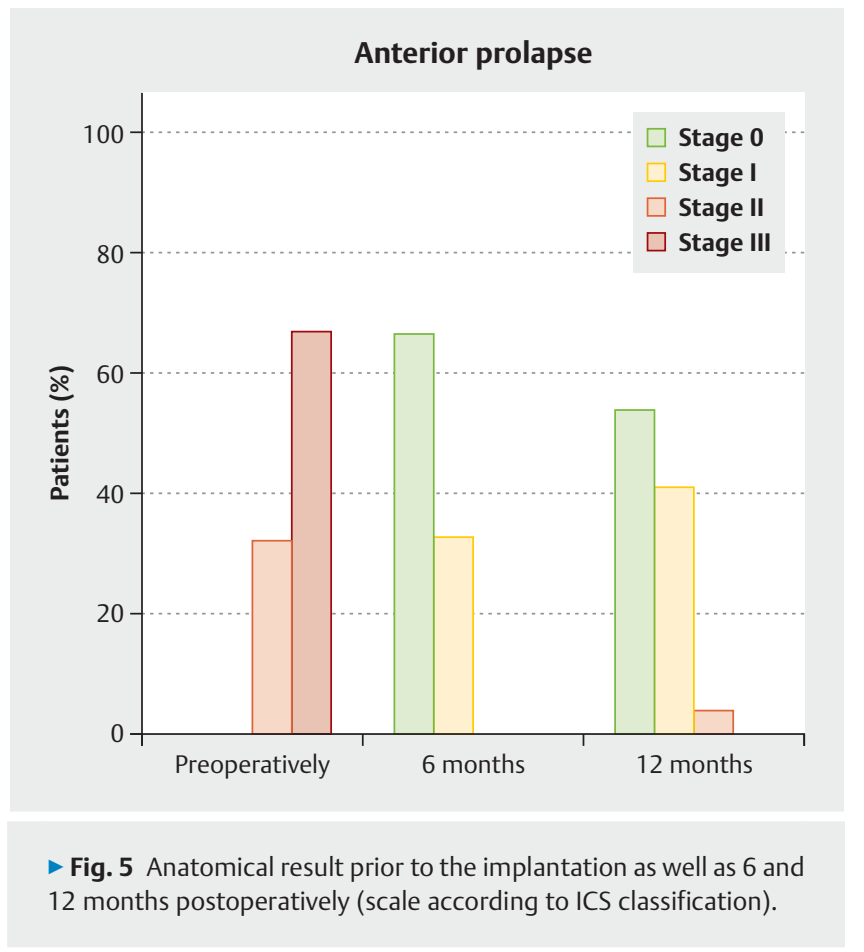

affected by AEs of the groups "Impairment of renal and/or bladder function" (11.5\% [6/52] of the patients) and "Symptoms of the reproductive system and/or chest discomfort" (5.7\% [3/52]).

The number of intra- or perioperative complications was extremely low. No organ damage was reported. A haematoma which required revision but not transfusion occurred in one patient $(1.9 \%[1 / 52]) .3 .8 \%(2 / 52)$ of patients received antibiotic treatment due to a urinary tract infection. 3.8\% (2/52) of the patients reported more severe postoperative pain (CTCAE grade 3 ) in the pelvis. One patient $(1.9 \%$ [1/52]) suffered continuous urine voiding disorder. Preoperatively, 53.8\% (28/52) of the patients were continent. $46.2 \%$ (24/52) of women suffered from grade I or II stress incontinence. At the 12-month follow-up, 73.5\% (36/ $49)$ of the patients were continent. $58.3 \%(21 / 36)$ of them did not demonstrate any incontinence symptoms, as was the case preoperatively. $36.1 \%(13 / 36)$ of the continent women at the 12 month follow-up did not demonstrate any postoperative symptoms of stress incontinence indicated previously, $11.1 \%$ (4/36) had received a suburethral sling placement in the course of the study. 5.5\% (2/36) due to symptoms which already existed preoperatively and $5.5 \%(2 / 36)$ due to marked stress incontinence postoperatively. $26.5 \%$ (13/49) of the patients indicated symptoms of stress incontinence at the time of the 12-month follow-up without the desire for surgical treatment. In $38.4 \%$ (5/13) of these women, masked grade I stress incontinence occurred postoperatively; in $61.6 \%(8 / 13)$ of the patients, the stress incontinence continued unchanged as compared to before the implantation. At no time in the study did erosion have to be reported as an AE. 


\section{Discussion}

The initial cases of surgical treatment of female organ prolapse using alloplastic materials were published in the mid-1950s. [29]. In these first cases, a tantalum mesh (oxidised metal) was initially implanted. Then, starting in the early 1960s, the rise of synthetic sutures and meshes began, initially in surgical hernia surgery but then also in prolapse surgery [30-33]. Given an ongoing discussion about materials [34] due to the high rate of complications (dyspareunia, shrinkage, pain, erosions, etc.) the implants were continuously developed further [35]. In the early 2000s, a polypropylene mesh with partially absorbable monophilic sutures and a pore size of $2.5 \mathrm{~mm}$ was considered to be the optimal material for alloplastic tissue replacement in the pelvic floor [36, 37], which is why this type of material was picked up on by many manufacturers and made available on the market in various forms of application. This and other implants were taken off the market following the warning from the FDA in 2011 [12] because of the wave of lawsuits in the United States and there was a significant decrease in mesh-aided prolapse surgeries. The situation in Europe was different. Although there was also a decrease here in the total number of implantations, the numbers among users who regularly performed vaginal mesh surgeries remained constant, as revealed by a survey among members of the International Urogynecology Association (IUGA) [38]. These changes can also be verified for Germany [14]. If an attempt is made in the case of a method with a high anatomical success rate [39], in comparison to the conventional surgeries with tightening of the autologous tissue $[3,7]$, to further reduce the rate of complications through improved elasticity of the material, enlarged mesh pores and weight reduction of the implant, new implants have been developed worldwide through cooperation with experienced mesh surgeons and the industry, and the positive effects for patients have been reappraised in studies [16, 40-42].

In the national, multicentre observational study presented here with 54 included patients, the changes in quality of life, impact on sexuality, the rate of complications and the anatomic result following implantation of a titanised polypropylene mesh were investigated in the case of a symptomatic cystocele. The patient cohort of this study reflects the patient clientele typical for Germany for the disease $[26,27]$. The study was designed as a follow-up study to the previous long-term study (clinicaltrials.gov: NCT01084889) for the investigation of cystocele correction with an alloplastic mesh (TiLOOP ${ }^{\circledR}$ Total 6, pfm medical ag) also with obturator, lateral and apical fixation $[11,43]$. Through the further improvement of the implant (enlargement of the pores from 1 to $3 \mathrm{~mm}$, weight reduction from 35 to $24 \mathrm{~g} / \mathrm{m}^{2}$ ), the positive results with regard to quality of life this time as the primary endpoint, sexuality (with an additional questionnaire) [17], and the anatomical result should be confirmed with the simultaneous expectation that the rate of complications would decrease.

The assessment of the P-QoL questionnaire on quality of life demonstrated a significant increase in patients' quality of life compared to the preoperative questionnaire not only 6 months postoperatively but also after 12 months. The study was thus able to confirm other published works and also the data from the previous study $[11,16,43-45]$. Overall, it is typical for this patient cohort that the majority of the women are not sexually active. In addition to symptomatic prolapse, the reasons for this are often problems on the part of the partner, age, or the patient's own state of health. The queries regarding sexuality, which were particularly detailed due to the addition of another 8 questions, revealed very encouraging results. Postoperatively (44.1\%) significantly more patients were sexually active than preoperatively (26.9\%). No previously sexually active patient was sexually inactive 12 months postoperatively. Only $2 \%(1 / 49)$ of the patients indicated dyspareunia as the reason for sexual inactivity 12 months postoperatively; preoperatively, this figure was $15.4 \%$, and no patient indicated de novo dyspareunia. Given a low number of patients, this can undoubtedly be seen only as a further indication of a positive influence on sexuality following vaginal mesh implantation which the TiLOOP ${ }^{\circledR}$-Total-6 study had already shown with a positive effect on sexuality [11]. However, it is suspected that the further change in the implant, especially the greater flexibility due to the reduced weight, could play a role here. Additional clinical studies with a larger number of cases are necessary to confirm this topic and also to compare the various vaginal surgery methods with one another. The anatomical result was very good. Only $4.3 \%$ (2/46) of the patients demonstrated a grade II cystocele again at the 12-month follow-up. Both patients had undergone hysterectomy and a posterior colporrhaphy was performed in parallel to the mesh implantation. Whether a mesh-aided surgical treatment of the posterior compartment can decrease the rate of recurrence even further here should be investigated in additional studies. Overall, this rate of recurrence, as other studies on mesh-aided prolapse surgery have shown $[11,44,46]$, is superior to that of autologous tissue reconstruction in the sense of anterior colporrhaphy [3,7]. Most of the 19 documented adverse events which occurred during the 12-month follow-up observation period can be attributed to the typical complications following surgical prolapse correction, e.g. urine voiding disorder, masked incontinence, urinary tract infection. There were no adverse events related to the investigational device. The TiLOOP ${ }^{\circledR}$-Total- 6 study demonstrated an erosion rate of $10.5 \%$ in the first 12 months [11]. In the widely discussed PROSPECT study, the most significant difference between conventional tightening of autologous tissue and mesh implantation was the rate of secondary procedures due to mesh erosion [47]. In the study described here, no individual cases of erosion occurred within 12 months. Long-term data with the new mesh implants must still undoubtedly confirm this positive result on larger numbers of patients. However, the data on quality of life, sexuality, and the complications presented here give an indication that, with the further development of implants, the surgical treatment of pelvic organ prolapse with the implantation of an alloplastic mesh has had fewer complications and has become more satisfactory for patients with regard to the postoperative quality of life, including sexuality. In the past 3 years, short-term as well as long-term data on vaginal mesh implantations have been continuously published $[43,44-46,48]$. This shows that this surgical method represents a treatment which is currently widely used. The Association for Urogynaecology (AGUB) has drawn up a statement on the prohibition by the FDA since April 2019 of alloplastic meshes for the anterior compartment [49]. Here as well, the guideline-compliant use of alloplastic 
meshes for the surgical correction of pelvic organ prolapse in women is highlighted as an important treatment option.

\section{Conclusion}

The surgical treatment of pelvic organ prolapse with the TiLOOP ${ }^{\circledR}$ PRO-A mesh as an alloplastic mesh implant demonstrates a very good anatomic result with a very low rate of recurrence. In the hand of the practised surgeon, the method has few complications. The quality of life improves in all areas significantly and the effects on sexuality are positive. In accordance with the guidelines, each patient should be counselled prior to surgical prolapse correction using the current data on the risk of recurrence with and without an implant, rates of complications, and on the therapeutic alternatives. It is desirable to offer all current therapeutic options in a urogynaecological centre. However, current surveys show that there is little agreement in the treatment of pelvic organ prolapse [50-52]. The data presented here and other longterm studies which compare methods, among others, should provide certainty and assistance now and in the future in the selection of the surgical method, especially for the patients and physicians.

\section{Acknowledgements}

We thank Dr. Angelika Greser for support in the concept and study design and Arim Shukri for the statistical data analyses. In addition, we thank Dr. Angelika Greser and Dr. Elke Nolte for their critical review of the manuscript.

\section{Conflict of Interest}

The authors confirm that there are no further conflicts beyond the conflicts of interest listed below. The activities listed did not have and do not have any influence on the study results or their publication.

Tina Cadenbach-Blome: Honoraria, consulting - pfm medical, Coloplast, DynaMesh; Markus Grebe: Honoraria - pfm medical; Mathias Mengel: Honoraria - pfm medical, AMI; Dr. Friedrich Pauli: Consulting - pfm medical; Christian Fünfgeld: Honoraria - pfm medical, Serag Wiessner, AMS, AMI, Astellas, Recordati, Promedon.

\section{References}

[1] Nygaard I, Barber MD, Burgio KL et al. Prevalence of symptomatic pelvic floor disorders in US women. JAMA 2008; 300: 1311-1316

[2] Ward RM, Velez Edwards DR, Edwards T et al. Genetic epidemiology of pelvic organ prolapse: a systematic review. Am J Obstet Gynecol 2014; 211: 326-335

[3] Deutsche Gesellschaft für Gynäkologie und Geburtshilfe (DGGG); Arbeitsgemeinschaft der Wissenschaftlichen Medizinischen Fachgesellschaften (AWMF). Diagnostik und Therapie des weiblichen Descensus genitalis. 2016. Online: https://www.awmf.org/uploads/tx_szleitlinien/ 015-006I_S2e_Descensus_genitalis-Diagnostik-Therapie_2016-11verlaengert.pdf; last access: 21.08.2019

[4] Slieker-ten Hove MC, Pool-Goudzwaard AL, Eijkemans M] et al. The prevalence of pelvic organ prolapse symptoms and signs and their relation with bladder and bowel disorders in a general female population. Int Urogynecol J Pelvic Floor Dysfunct 2009; 20: 1037-1045

[5] Smith FJ, Holman CD, Moorin RE et al. Lifetime risk of undergoing surgery for pelvic organ prolapse. Obstet Gynecol 2010; 116: 1096-1100
[6] Wu JM, Hundley AF, Fulton RG et al. Forecasting the prevalence of pelvic floor disorders in U.S. Women: 2010 to 2050. Obstet Gynecol 2009; 114 : 1278-1283

[7] Dietz HP, Hankins KJ, Wong V. The natural history of cystocele recurrence. Int Urogynecol ] 2014; 25: 1053-1057

[8] Denman MA, Gregory WT, Boyles SH et al. Reoperation 10 years after surgically managed pelvic organ prolapse and urinary incontinence. Am J Obstet Gynecol 2008; 198: 555.e1-555.e5

[9] Maher C, Feiner B, Baessler $\mathrm{K}$ et al. Transvaginal mesh or grafts compared with native tissue repair for vaginal prolapse. Cochrane Database Syst Rev 2016; (2): CD012079

[10] Caquant F, Collinet P, Debodinance P et al. Safety of Trans Vaginal Mesh procedure: retrospective study of 684 patients. J Obstet Gynaecol Res 2008; 34: 449-456

[11] Funfgeld C, Stehle M, Henne B et al. Quality of Life, Sexuality, Anatomical Results and Side-effects of Implantation of an Alloplastic Mesh for Cystocele Correction at Follow-up after 36 Months. Geburtsh Frauenheilk 2017; 77: 993-1001

[12] US Department of Health and Human Services; Food and Drug Administration; Center for Devices and Radiological Health et al. UPDATE on Serious Complications Associated with Transvaginal Placement of Surgical Mesh for Pelvic Organ Prolapse. FDA Safety Communication. 2011. Online: http://2015.iuga.org/wp-content/uploads/workshops/ws29_ literature7.pdf; last access: 21.08.2019

[13] FDA. FDA news release, FDA takes action to protect women's health, orders manufacturers of surgical mesh intended for transvaginal repair of pelvic organ prolapse to stop selling all devices. 16.04.2019. Online: https://www.fda.gov/news-events/press-announcements/fda-takesaction-protect-womens-health-orders-manufacturers-surgical-meshintended-transvaginal; last access: 21.08.2019

[14] INEK [Institut für das Entgeltsystem im Krankenhaus]. Abfrage der Anzahl der Fälle mit OPS Codes zur Behandlung des Descensus genitalis im DRG Browser (§21 KHEntgG) von 1.1.2007- 31.12.2012: 5-704.01 Kolporrhaphia anterior mit alloplastischem Material, 5-704.11 Kolporrhaphia posterior mit alloplastischem Material und 5-704.4 g Scheidenstumpffixation vaginal, mit alloplastischem Material

[15] Guyomard A, Delorme E. Transvaginal treatment of anterior or centra urogenital prolapse using six tension-free straps and light mesh. Int J Gynaecol Obstet 2016; 133: 365-369

[16] Yesil A, Watermann D, Farthmann J. Mesh implantation for pelvic organ prolapse improves quality of life. Arch Gynecol Obstet 2013. doi:10.1007/s00404-013-3052-0

[17] Farthmann J, Mengel M, Henne B et al. Improvement of pelvic floor-related quality of life and sexual function after vaginal mesh implantation for cystocele: primary endpoint of a prospective multicentre trial. Arch Gynecol Obstet 2016; 294: 115-121

[18] Haylen BT, de Ridder D, Freeman RM et al. An International Urogynecological Association (IUGA)/International Continence Society (ICS) joint report on the terminology for female pelvic floor dysfunction. Neurourol Urodyn 2010; 29: 4-20

[19] Bump RC, Mattiasson A, Bo Ket al. The standardization of terminology of female pelvic organ prolapse and pelvic floor dysfunction. Am J Obstet Gynecol 1996; 175: 10-17

[20] Persu C, Chapple CR, Cauni V et al. Pelvic Organ Prolapse Quantification System (POP-Q) - a new era in pelvic prolapse staging. J Med Life 2011; 4: 75-81

[21] Digesu GA, Khullar V, Cardozo L et al. P-QOL: a validated questionnaire to assess the symptoms and quality of life of women with urogenital prolapse. Int Urogynecol J Pelvic Floor Dysfunct 2005; 16: 176-181

[22] Wedel T, Pauli F. Anatomische und chirurgische Grundlagen zur Netzrekonstruktion des Beckenbodens. Stuttgart: Thieme; 2010 
[23] Lenz F, Stammer H, Brocker K et al. Validation of a German version of the P-QOL Questionnaire. Int Urogynecol J Pelvic Floor Dysfunct 2009; 20: 641-649

[24] Baessler K, Kempkensteffen C. [Validation of a comprehensive pelvic floor questionnaire for the hospital, private practice and research]. Gynakol Geburtshilfliche Rundsch 2009; 49: 299-307

[25] National Cancer Institute. Common Terminology Criteria for Adverse Events (CTCAE) 4.03. Bethesda, Maryland, USA: National Cancer Institute; 2010

[26] Statistisches Bundesamt. Results of Microcensus 2017. 18.03.2019 12211-0082 - Durchschnittliche Körpergröße, durchschnittliches Körpergewicht, durchschnittlicher Body-Mass-Index: Deutschland, Jahre, Geschlecht, Familienstand, Altersgruppen. Online: https://www. destatis.de; last access: 04.04.2019

[27] Institut für das Entgeltsystem im Krankenhaus. G-DRG V2013 Browser 2016 § 21 KHEntgG. 2017. Online: http://www.g-drg.de/content/view/ full/4887; last access: 04.04.2019

[28] Schulz KF, Altman DG, Moher D et al. CONSORT 2010 statement: updated guidelines for reporting parallel group randomized trials. Ann Intern Med 2010; 152: 726-732

[29] Moore J, Armstrong JT, Willis SH. The use of tantalum mesh in cystocele with critical report of ten cases. Am J Obstet Gynecol 1955; 69: 11271135

[30] Usher FC. Hernia repair with Marlex mesh. An analysis of 541 cases. Arch Surg 1962; 84: 325-328

[31] Lane FE. Repair of posthysterectomy vaginal-vault prolapse. Obstet Gynecol 1962; 20: 72-77

[32] Stanton SL, Cardozo LD. Results of the colposuspension operation for incontinence and prolapse. Br J Obstet Gynaecol 1979; 86: 693-697

[33] Julian TM. The efficacy of Marlex mesh in the repair of severe, recurrent vaginal prolapse of the anterior midvaginal wall. Am J Obstet Gynecol 1996; 175: 1472-1475

[34] Cosson M, Debodinance P, Boukerrou M et al. Mechanical properties of synthetic implants used in the repair of prolapse and urinary incontinence in women: which is the ideal material? Int Urogynecol J Pelvic Floor Dysfunct 2003; 14: 169-178; discussion 178

[35] Boukerrou M, Boulanger L, Rubod C et al. Study of the biomechanical properties of synthetic mesh implanted in vivo. Eur J Obstet Gynecol Reprod Biol 2007; 134: 262-267

[36] Fatton B, Amblard J, Debodinance P et al. Transvaginal repair of genital prolapse: preliminary results of a new tension-free vaginal mesh (Prolift technique)-a case series multicentric study. Int Urogynecol J Pelvic Floor Dysfunct 2007; 18: 743-752

[37] Milani AL, Hinoul P, Gauld JM et al. Trocar-guided mesh repair of vaginal prolapse using partially absorbable mesh: 1 year outcomes. Am J Obstet Gynecol 2011; 204: 74-78

[38] Ghoniem G, Hammett J. Female pelvic medicine and reconstructive surgery practice patterns: IUGA member survey. Int Urogynecol J 2015; 26 : 1489-1494
[39] Pécheux O, Giraudet G, Drumez E et al. Long-term (8.5 years) analysis of the type and rate of reoperation after transvaginal mesh repair (Prolift $\left.{ }^{\circledR}\right)$ in 349 patients. Eur J Obstet Gynecol Reprod Biol 2019; 232: 33-39

[40] Palma PCR, Monteiro MVC, Ledesma MA et al. Treatment of Anterior Vaginal Wall Prolapse Using Transvaginal Anterior Mesh With Apical Fixation: A Prospective Multicenter Study With up to 2 Years of Follow-up. Int Neurourol J 2018; 22: 177-184

[41] Levy G, Padoa A, Fekete Z et al. Self-retaining support implant: an anchorless system for the treatment of pelvic organ prolapse-2-year follow-up. Int Urogynecol ] 2017. doi:10.1007/s00192-017-3415-3

[42] Chang YW, Chuang FC, Wu LY et al. Evaluating the efficacy of the singleincision uphold system for pelvic organ prolapse repair. Taiwan J Obstet Gynecol 2019; 58: 94-98

[43] Fünfgeld C, Cadenbach-Blome T, Mengel M et al. Development of POPrelated Symptoms, Quality of Life, Anatomical Results and Side Effects after Cystocele Correction with an Improved Titanized Mesh. International Society of Pelviperineology Congress. Bucharest; 2018

[44] Rahkola-Soisalo P, Altman D, Falconer C et al. Quality of life after Uphold Vaginal Support System surgery for apical pelvic organ prolapse-A prospective multicenter study. Eur J Obstet Gynecol Reprod Biol 2017; 208: $86-90$

[45] Hüsch T, Mager R, Ober E et al. Quality of life in women of non-reproductive age with transvaginal mesh repair for pelvic organ prolapse: A cohort study. Int J Surg 2016; 33 Pt A: 36-41

[46] Buca DIP, Liberati M, Falo E et al. Long-term outcome after surgical repair of pelvic organ prolapse with Elevate Prolapse Repair System. J Obstet Gynaecol 2018; 38: 854-859

[47] Glazener CM, Breeman S, Elders A et al. Mesh, graft, or standard repair for women having primary transvaginal anterior or posterior compartment prolapse surgery: two parallel-group, multicentre, randomised, controlled trials (PROSPECT). Lancet 2017; 389: 381-392

[48] Mateu Arrom L, Errando Smet C, Gutierrez Ruiz C et al. Pelvic Organ Prolapse Repair with Mesh: Mid-Term Efficacy and Complications. Urol Int 2018; 101: 201-205

[49] Naumann G, Gabriel B, Baessler K et al. Stellungnahme zur FDA Entscheidung des Verbotes von vaginalen Netzen im vorderen Scheidenbereich April 2019. Online: https://www.dggg.de/leitlinien-stellungnahmen/ stellungnahmen/fda-entscheidung-des-verbotes-von-vaginalen-netzenim-vorderen-scheidenbereich-1063/; last access: 21.08.2019

[50] Vermeulen CKM, Coolen A, Spaans WA et al. Treatment of vaginal vault prolapse in The Netherlands: a clinical practice survey. Int Urogynecol J 2018. doi:10.1007/s00192-018-3832-y

[51] Fairclough E, Myers ], Smith ARB et al. A UK questionnaire survey of current techniques used to perform pelvic organ prolapse repair. Int Urogynecol J 2017; 28: 1367-1376

[52] Coolen AWM, Bui BN, Dietz V et al. The treatment of post-hysterectomy vaginal vault prolapse: a systematic review and meta-analysis. Int Urogynecol J 2017; 28: 1767-1783 